\title{
Living donor liver transplantation for neonatal hemochromatosis using non-anatomically resected segments II and III: a case report
}

\author{
Amit Sharma*, Adrian H Cotterell, Daniel G Maluf, Marc P Posner, Robert A Fisher
}

\begin{abstract}
Introduction: Neonatal hemochromatosis is the most common cause of liver failure and liver transplantation in the newborn. The size of the infant determines the liver volume that can be transplanted safely without incurring complications arising from a large graft. Transplantation of monosegments II or III is a standard method for the newborns with liver failure.

Case presentation: A three-week old African-American male neonate was diagnosed with acute liver failure secondary to neonatal hemochromatosis. Living-related liver transplantation was considered after the failure of intensive medical therapy. Intra-operatively a non-anatomical resection and transplantation of segments II and III was performed successfully. The boy is growing normally two years after the transplantation.

Conclusion: Non-anatomical resection and transplantation of liver segments II and III is preferred to the transplantation of anatomically resected monosegements, especially when the left lobe is thin and flat. It allows the use of a reduced-size donor liver with intact hilar structures and outflow veins. In an emergency, living-related liver transplantation should be offered to infants with liver failure secondary to neonatal hemochromatosis who fail to respond to medical treatment.
\end{abstract}

\section{Introduction}

Neonatal hemochromatosis $(\mathrm{NH})$, although rare, is the most common cause of liver failure and liver transplantation in neonates. Liver transplantation is the main therapy for infants who fail to respond to medical treatment [1]. Liver transplantation using either monosegment II or III $[2,3]$ is a technically challenging option that is especially beneficial for small infants in whom a left lateral segment [4] is large-for-size. We report that non-anatomical resection and transplantation of segments II and III may be a simpler, yet effective, surgical option for neonates with liver failure.

\section{Case presentation}

A three-week old African-American male newborn, weighing $2.5 \mathrm{~kg}$, was admitted to our unit with jaundice, abdominal distension and hepatomegaly. The pregnancy

\footnotetext{
* Correspondence: asharma@mcvh-vcu.edu; rafisher@vcu.edu Department of Surgery, Hume-Lee Transplant Center, Virginia Commonwealth University, PO Box 980057, Richmond, Virginia 23298-0057,
} USA

(c) 2010 Sharma et al; licensee BioMed Central Ltd. This is an Open Access article distributed under the terms of the Creative Commons Attribution License (http://creativecommons.org/licenses/by/2.0), which permits unrestricted use, distribution, and reproduction in any medium, provided the original work is properly cited. had been uncomplicated and there was no family history of metabolic or liver disease.

Laboratory studies for liver failure revealed a total serum bilirubin of $22.5 \mathrm{mg} / \mathrm{dL}$, an international normalized ratio 4.9 , aspartate aminotransferase $45 \mathrm{U} / \mathrm{L}$ and alanine aminotransferase $23 \mathrm{U} / \mathrm{L}$. The boy had a serum iron of $157 \mu \mathrm{g} / \mathrm{dL}$ (normal 30-165 $\mu \mathrm{g} / \mathrm{dL}$ ), serum ferritin $994 \mathrm{ng} / \mathrm{mL}$ (normal 30-330 $\mathrm{ng} / \mathrm{mL}$ ), serum transferrin $103 \mathrm{mg} / \mathrm{dL}$ (normal 215-380 mg/dL) and transferrin saturation $109 \%$ (range 16\%-60\%). He had an elevated alpha-fetoprotein level $(3289 \mathrm{ng} / \mathrm{mL})$. Investigations for infectious and inherited metabolic pathologies were negative. Magnetic resonance imaging (MRI) of the abdomen was suggestive of iron deposition in the liver, with conventional, patent arterial and venous anatomy. $\mathrm{NH}$ was suspected and confirmed by minor salivary

Medical therapy consisting of anti-oxidants and chelation with desferroxamine was initiated. As there was a progressive worsening of the boy's condition on medical therapy, his mother volunteered to be a living liver gland biopsy from the lower lip. 
donor. After a standard expedited two-day donorworkup, the related living donor liver transplantation was planned. Pre-operative MRI showed that the mother's left lateral segment volume was approximately $200 \mathrm{cc}^{3}$. We therefore decided to do a left lateral resection with back-table monosegmentectomy followed by transplantation.

Intra-operatively, after isolation of the mother's left hepatic artery, hepatic duct and portal branch, the hepatic parenchyma of segment IV was transected $5 \mathrm{~mm}$ to the right of the falciform ligament without blood inflow occlusion or graft manipulation. The segment II and III ducts united, just lateral to the umbilical portion of the left portal vein and the segment IV duct, then joined medial to umbilical portion. This confluence of segment II and III ducts was divided and used for anastomosis in the recipient. This was a thin 'pancake' left lateral segment that was transected using ultrasound guidance. On the back-table, a $2.5 \mathrm{~mm}$ endostapler with two, triplestaggered rows of titanium staples (Autosuture ${ }^{\mathrm{rm}} \mathrm{GIA}^{\mathrm{rm}} \mathrm{U}$ NIVERSAL stapler, US Surgical, Division of Tyco Healthcare Group LP, CT, USA) was used to staple and divide across the mid-portion of the left lateral segment just to the left of the secondary portal vasculature branching (Figure 1). The final graft consisted of the confluence of segment II and III bile ducts, left portal vein, left hepatic artery arising from left gastric artery and two in-proximity left hepatic veins, joined as one. This non-anatomically resected portion of the lateral segment was used for transplantation in standard piggyback fashion with Roux-en-Y jejuno-biliary anastomosis. The discarded part was used for hepatocyte isolation [5]. Heparin and aspirin were used in the first postoperative week to prevent vascular thrombosis. The patient was re-explored in the first week for clot evacuation around the transplanted liver segments, with no active bleeding on the cut surface or the stapled edge. Patient was discharged home after three weeks and continues to do well two years post-transplant.

\section{Discussion}

Neonatal hemochromatosis is a syndrome with an aggressive course and a poor prognosis. The etiopathogenesis is not very clear although siderosis resulting from infections, genetics and auto-immunity may play a role [6]. The pregnancy may be complicated by intrauterine

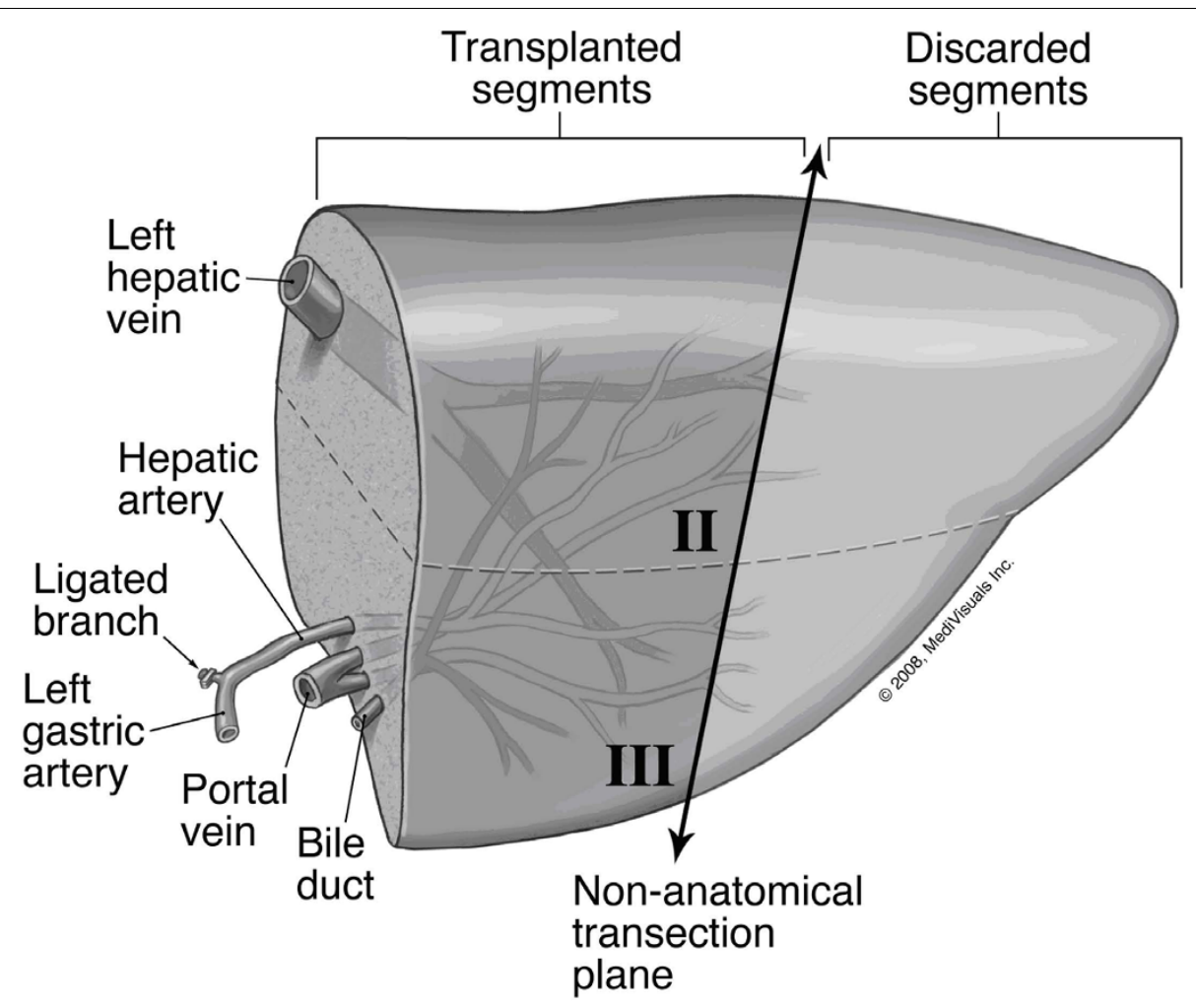

Figure 1 Liver segments II and III with reconstructed hilar structures just before non-anatomical resection. The donor had a left hepatic arterial branch arising from the left gastric artery and two left hepatic vein tributaries draining into the supra-hepatic vena cava. The final arrangement of the left portal vein, the reconstructed hepatic veins, replaced left hepatic artery arising from the left gastric artery and the bile duct is demonstrated here. On the back-table, transection was carried through segments II and III along a non-anatomical plane (thick black line) using an endovascular stapling device. 
growth restriction, oligohydramnios or still birth. The neonate may present with signs of hepatic insufficiency within hours of birth. Abnormal laboratory parameters include: decreased transferrin; ceruloplasmin; increased ferritin (non-specific, > $800 \mathrm{ng} / \mathrm{mL}$ ); mixed hyperbilirubinaemia; low aminotransferases; low factors V and VII ( $<10 \%$ of normal); thrombocytopenia, anaemia and increased alpha-fetoprotein ( $>200 \mathrm{ng} / \mathrm{mL}$ ). Hepatic and extra-hepatic siderosis with reticuloendothelum sparing is diagnostic of NH. Lower lip biopsy is safe and convenient for documenting siderosis in minor salivary glands. MRI is used to support the diagnosis of $\mathrm{NH}$ and is characterised by low signal intensity on $\mathrm{T} 2$ weighted liver images [7]. Since NH recurs in $75-80 \%$ of siblings, the parents should be discouraged from having any further pregnancies. Gestational high dose intravenous immunoglobulin administered to the mother, from 18 weeks to birth, appears to decrease the lethality of recurrent neonatal hemochromatosis [8]. Medical therapy with desferrioxamine and antioxidant cocktail ( $\mathrm{N}$-acetylcysteine, vitamin E, prostaglandin E1 and selenium), although not highly successful, are still used to treat neonates. Liver transplantation is considered to be the treatment of choice for infants not responding to medical therapy. Early medical therapy results in a $10 \%-20 \%$ survival rate while long-term survival after liver transplantation may range from $50 \%$ to $66 \%$ [1].

Liver transplantation using either monosegment II or III is a useful option for small infants in whom a whole left lateral segment is large-for-size [4]. Monosegment transplantation is mostly used for infants with a calculated graft-to-recipient weight ratio of less than or equal to $4.0 \%$ when using the left lateral segment. Splitting of the left lateral segment can be been done either in situ in the donor or on the back-table. Despite these surgical innovations, neonatal liver transplantation still poses challenges because of the size of the recipients who usually weigh less than $10 \mathrm{~kg}$ [9]. Depending on the donor size, even the transplanted monosegment may be large-for-size and make graft placement technically difficult and may lead to post-operative complications [10]. More importantly, the use of a segment II or III may result in a smaller diameter bile duct that may be more prone to strictures and leaks as the liver regenerates [1]. In our report, the left lateral segment was split along a non-anatomical plane and the confluence of segments II and III bile ducts provided us with a larger caliber $(4 \mathrm{~mm})$ duct in the donor segments. The caliber of the hepatic and the portal veins used for anastomosis were the same as when using a complete left lateral segment. The use of a stapling device made this division technically easier and more efficient. However, the stapled edge may be prone to bleeding after reperfusion. This can be minimized by selecting thin and flat left lateral segments for stapling. This case also demonstrates that emergent living-related liver transplantation is a viable option for neonates with acute liver failure who may not survive the time spent on the waiting list for a whole or a split-liver from a deceased donor.

\section{Conclusion}

Urgent living-related liver transplantation should be offered to infants with acute liver failure secondary to neonatal hemochromatosis who are non-responsive to medical therapy. The left lateral segment can be reduced in size, especially when it is flat (like a pancake), by splitting it along a non-anatomical plane. This simple technique allows the use of the confluence of donor segment II and III bile ducts that are less prone to stricturing due to their larger caliber. However, this advantage may be lost in cases where the segment II and III bile ducts join separately, medial to the umbilical portion of the portal vein.

\section{Consent}

Written informed consent was obtained from the patient's mother for publication of this case report and any accompanying images. A copy of the written consent is available for review by the Editor-in-Chief of this journal.

\section{Abbreviations}

IUGR: intrauterine growth restriction; MRI: magnetic resonance imaging; $\mathrm{NH}$ : neonatal hemochromatosis.

\section{Acknowledgements}

We would like to thank Mr Jose Rodriguez for his technical help in the drafting of this manuscript.

\section{Authors' contributions}

AS collected data, designed and wrote the manuscript. AHC was a major contributor to the manuscript. DGM assisted in the critical revisions of the manuscript. MPP reanalyzed the surgical facts and provided comments on the critical intellectual content of the manuscript. RAF helped to conceive, critically revise and write the manuscript. All authors read and approved the final manuscript.

\section{Competing interests}

The authors declare that they have no competing interests.

Received: 25 March 2010 Accepted: 19 November 2010 Published: 19 November 2010

\section{References}

1. Rodrigues F, Kallas M, Nash R, Cheeseman P, D'Antiga L, Rela M, Heaton ND, Mieli-Vergani G: Neonatal hemochromatosis-medical treatment vs transplantation: the king's experience. Liver Transp/ 2005 11:1417-1424.

2. de Santibañes E, McCormack L, Mattera J, Pekolj J, Sívori J, Beskow A, D'Agostino D, Ciardullo M: Partial left lateral segment transplant from a living donor. Liver Transp/ 2000, 6:108-112.

3. Srinivasan P, Vilca-Melendez H, Muiesan P, Prachalias A, Heaton ND, Rela M: Liver transplantation with monosegments. Surgery 1999, 126:10-12.

4. Broelsch CE, Whitington PF, Emond JC, Heffron TG, Thistlethwaite JR, Stevens L, Piper J, Whitington SH, Lichtor JL: Liver transplantation in children from living related donors. Surgical techniques and results. Ann Surg 1991, 214:428-437. 
5. Fisher RA, Strom SC: Human hepatocyte transplantation: worldwide results. Transplantation 2006, 82:441-449.

6. Sigurdsson L, Reyes J, Kocoshis SA, Hansen TW, Rosh J, Knisely AS: Neonatal hemochromatosis: outcomes of pharmacologic and surgical therapies. J Pediatr Gastroenterol Nutr 1998, 26:85-89.

7. Udell IW, Barshes NR, Voloyiannis T, Lee TC, Karpen SJ, Carter BA, Finegold M, Goss JA: Neonatal hemochromatosis: radiographical and histological signs. Liver Transp/ 2005, 11:998-1000.

8. Whitington PF, Hibbard JU: High-dose immunoglobulin during pregnancy for recurrent neonatal haemochromatosis. Lancet 2004, 364:1690-1698.

9. Enne M, Pacheco-Moreira L, Balbi E, Cerqueira A, Santalucia G, Martinho JM: Liver transplantation with monosegments. Technical aspects and outcome: a meta-analysis. Liver Transpl 2005, 11:564-569.

10. Ogawa K, Kasahara M, Sakamoto S, Ito T, Taira K, Oike F, Ueda M, Egawa H, Takada Y, Uemoto S: Living donor liver transplantation with reduced monosegments for neonates and small infants. Transplantation 2007, 83:1337-1340.

doi:10.1186/1752-1947-4-372

Cite this article as: Sharma et al: Living donor liver transplantation for neonatal hemochromatosis using non-anatomically resected segments II and III: a case report. Journal of Medical Case Reports 2010 4:372.

\section{Submit your next manuscript to BioMed Central} and take full advantage of:

- Convenient online submission

- Thorough peer review

- No space constraints or color figure charges

- Immediate publication on acceptance

- Inclusion in PubMed, CAS, Scopus and Google Scholar

- Research which is freely available for redistribution

Submit your manuscript at www.biomedcentral.com/submit
Ciomed Central 